\title{
Obituary
}

\section{Thorstein Guthe MD}

Thorstein Guthe, an Honorary Life Member of the Medical Society for the Study of Venereal Diseases, died recently in his native Norway, aged 82 .

His name was well known throughout the world for more than the first quarter century of the World Health Organisation. He was Chief of its Venereal Diseases and Treponematosis Division. His consistently sustained endeavours, aimed at prevention and control of infections, commanded unsurpassed regard and admiration. He was in every way a big man with a great gift for winning hearts and minds to his causes.

Thorstein Guthe was born in Oslo in 1912 and graduated in medicine from the local University. He soon proceeded overseas to undertake post-graduate studies and research in several prestigious centres. These included the Mayo Clinic (Internal Medicine and Dermatology), Johns Hopkins University (Public Health, Epidemiology and Tropical Medicine), the Institute Pasteur and London University (Microbiology and Serology).

He was a fine linguist. His spoken and written English had that precision and clarity reserved for a distinguished few-all authors of note. In addition, he had time and energy for athletics, representing Norway in fencing at the Olympic Games. During the Second World War he was with that part of the Royal Norwegian Navy which served with the Allied Forces. He was awarded the Distinguished Service Medal by King Haakon VII.

With the end of hostilities he returned to Norway to face the awesome problems of its reconstruction. He was soon involved as Assistant Director of Public Health. In 1946 he was invited to join the Interim Commission set up to plan the World Health Organisation. With the establishment of that Special Agency of the United Nations he joined its communicable disease programme. His responsibilities focused on venereal diseases and later were expanded to include the treponematoses. In the earlier years he directed his attention to epidemiological and laboratory aspects, promoting screening programmes and improved diagnosis. By mustering WHO's staff at its six Regional Offices he was able to report in terms of prevalence and incidence. A regular series of reports showed the benefits in terms of screening results, treatment regimes and follow-up findings. Thus Guthe increased the priority given by national public health services to the sexually transmitted diseases and the treponematoses. His persuasive enthusiasm was infectious.

Guthe had an eye for detail. He was the originator of the cryobiological method of absolute preservation and transport of micro-biological specimens at $-200^{\circ} \mathrm{C}$ in what became known as the "liquid nitrogen can".

Guthe's dynamic and comprehensive leadership was found acceptable by more and more governments as well as non- governmental agencies such as those affiliated to the International Union Against the Venereal Diseases. Organising such endeavours as the WHO Syphilis Study Commission for three months in the USA in 1949 and the First International Yaws Conference in Thailand in 1952, set the standard for regular Regional Seminars and
Symposia. While he assembled expert Committees at WHO's central office in Geneva and distributed their Reports world wide, he also recruited consultants to make reports on individual countries and assembled and dispatched "demonstration teams" to undertake local training, surveys, mass treatment endeavours and followup examinations. In his later years he encouraged WHO's Regional Offices to develop their own Centres of Excellence and Training as clear evidence of progress.

Again his attention to detail is evidenced. He addressed, for example, the special needs of seafarers, the elimination of bejel in Bosnia and ensured financial support for the work and publication of "The Oslo Study of Untreated Syphilis" in 1955.

Guthe's personal qualities of intellect, personality, energy and organisational skills made him very much the right man in the right place at the right time. His contribution to public health was as great as it was global. Few physicians have so influenced, directly and indirectly, the health of so many in so many countries.

In retirement he regularly enjoyed holidays in the summer cabin he built himself on a small uninhabited island. Thorstein was a generous host, a considerate guest and with his wide range of interests and hobbies a stimulating companion.

All who knew him will be greatly saddened to learn of his demise.

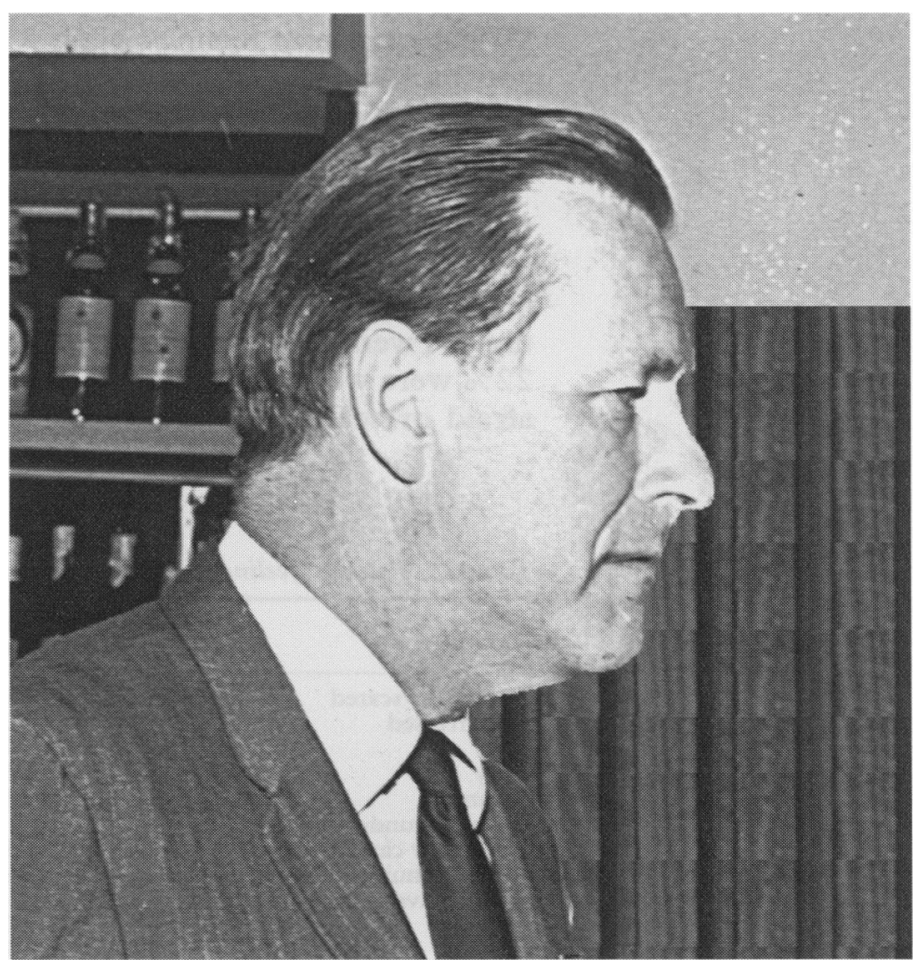

SML RSM

Dr Thorstein Guthe 